\title{
The complete human being, energy and soul
}

\author{
Lucian T. MÂNDREA \\ University Politehnica of Bucharest, Bucharest, Romania \\ mandrea_lucian@hotmail.com, lucian.mandrea@upb.ro \\ Aurel I. CHIRILĂ \\ University Politehnica of Bucharest, Bucharest, Romania
}

\begin{abstract}
The scope of the research is to investigate and to present the human being as a whole. The article presents a series of experiments regarding the human being. It reveals, based on proven facts, such as video footages and scientific measurements, that the human being is not only just a simple physical body. It is a complex structure with an energy shell and a soul with an essential role and these details have to be studied more thoroughly in the future. As the human body uses energy, specific measurement practices are applied. The authors used an Electro Photonic Imaging Device and a Thermal Vision Camera Device because the measured energy frequencies are not within the optical visual frequency range. The general and the detailed human body health state can be evaluated using the EPI Device. Despite the classical medicine approach that considers only the physical component of the body, the article proves the existence and reveals a wider behavior of the human being from the supplementary point of view which is often called spirit, soul, ethereal body or just entity. It is also shown that the human being is capable of evaluating and healing by own means. Thus, a study case is presented regarding the health state evolution during a period of one year, while the human body is continuously taking care of itself. The complete control of the entire human being leads to a continuous good health and also to a good physical and psychic state, with increased performances in all activities. All these achievements can be useful to also obtain a very good job. The objective of the authors are to proof that the soul exists and also that every person can act to improve the own health, the general state and so to rich easier the happiness.
\end{abstract}

Keywords: energy, soul, human being, health, physical state, psychic state, performance.

\section{Introduction}

The humanity's common health problems related to the limitations of the classical medicine which is concerned only with the physical problems of the human body bring into discussion the human being as an entity.

The overtaking of the world's boundaries reveals the human being as a more complex structure whose examination could solve many problems.

The authors present both original videos and measurements which show the components of the human being, body and soul.

Particular skills of the first author are exercised to maintain the energy shell, the health, the physical and the psychic states in a very good condition. The authors consider that basic abilities to reach these goals can be achieved by everybody in time.

During the experiments an Electro Photonic Imaging Device and a Thermo Vision Camera have been employed in order to explore the behavior of the emotional pressure, the energy, the balance of a human being and the energy emissions towards the environment.

Comparisons are performed between the measurements of two successive years. Due to special actions, the energy level of the subject increases with $2 \%$, while the balance level also increases with more than $1.5 \%$, even though the subject is one year older. 


\section{The Experiments}

\section{The Orb's journeys}

The first experiment has been done to clearly prove that from time to time, during the rest periods of time, that is sleeping, the human being may behave surprisingly, as the great majority of people may say. For this reason, a video camera has been installed during the sleeping time and the human being activity has been monitored.

The authors present in Figure 1 a processed image resulting from successive overlapping frames of a recorded video footage that lasts a few seconds.

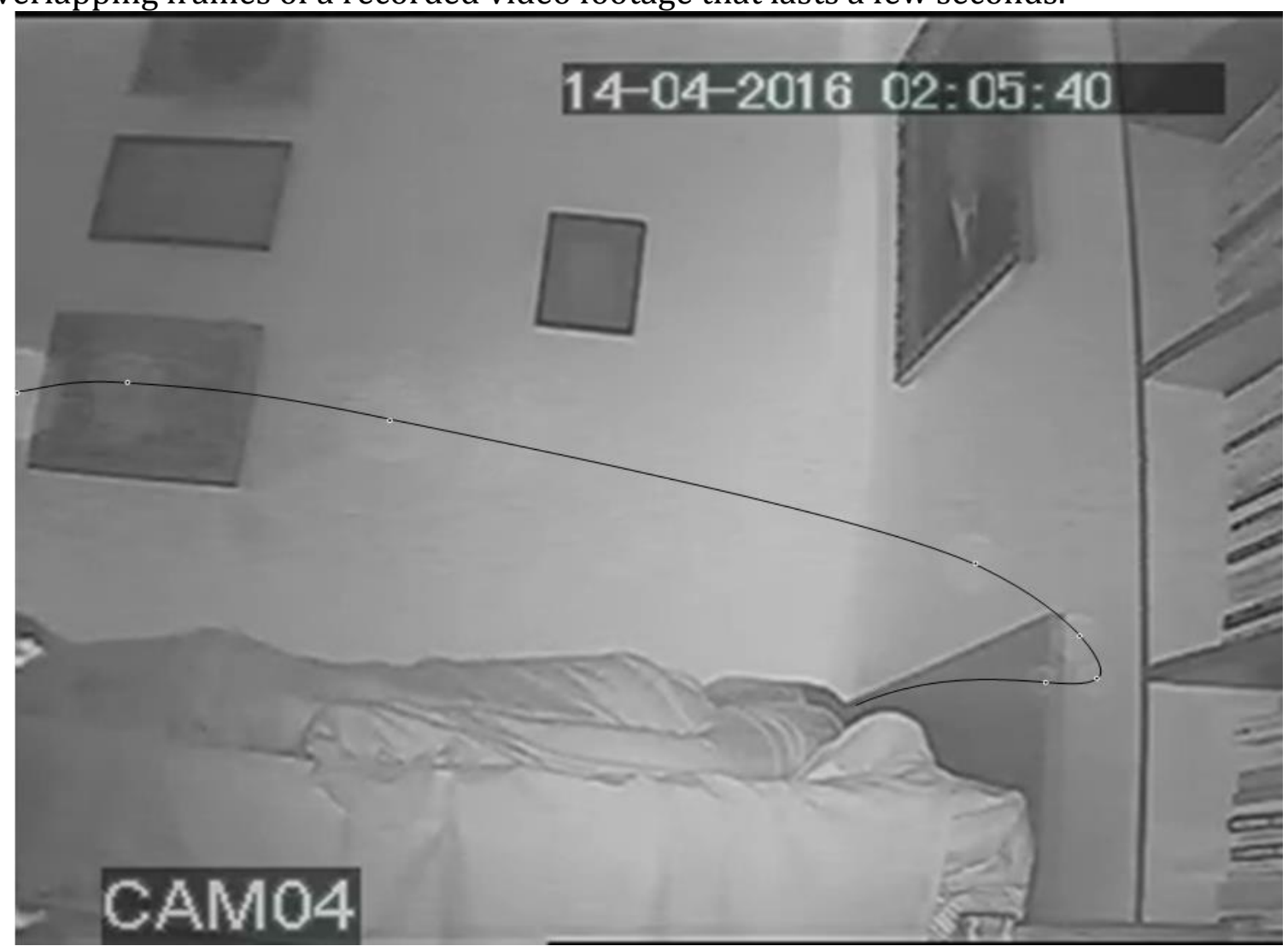

Figure 1. The departure of the glowing translucent orb (Subject: Lucian MÂNDREA)

Source: Authors' own property.

The trajectory of a moving glowing translucent orb is highlighted by a curve.

The orb is getting out of the body by starting from the upper part of the head and afterwards it returns by almost 180 degrees floating away from the body.

By post-processing the video frames it has been calculated that the speed of the orb in the central part of the image is around $0.5 \mathrm{~m} / \mathrm{s}$ (i.e. $1.8 \mathrm{~km} / \mathrm{h}$ ).

The second presented video footage also lasts a few seconds. A similar post processing is performed; thus the result is depicted in Figure 2. This time the glowing translucent orb is returning and it enters back into the body, again at the head level. 


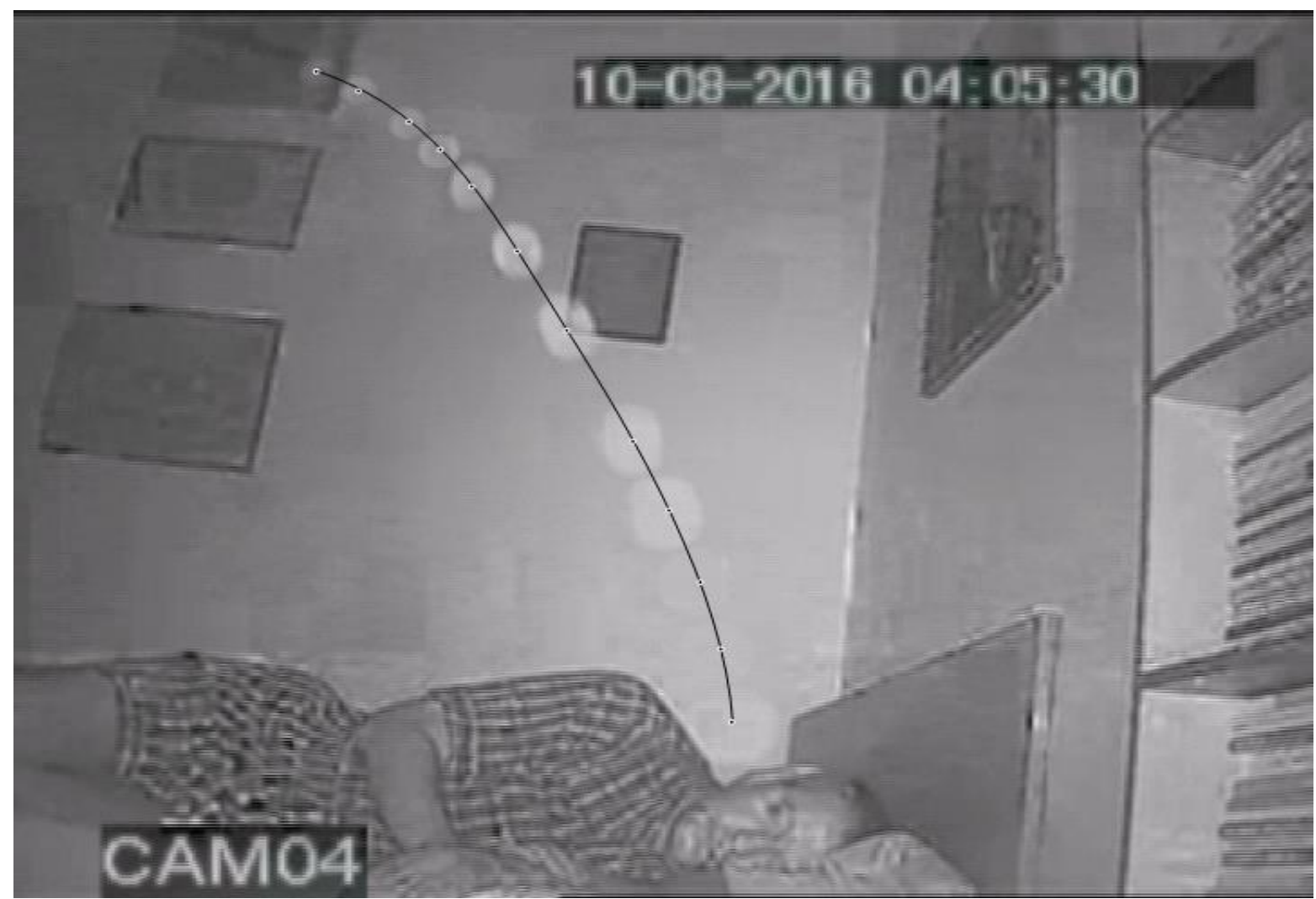

PICBE $\mid 429$

Figure 2. The arrival of the glowing translucent orb (Subject: Lucian MÂNDREA)

Source: Authors' own property.

The two videos are a small part of larger video footages that have been recorded during all the nights. They have the purpose to demonstrate that sometimes the glowing orb travels during the night. It is not getting out of the body only when we die.

This glowing orb is usually called spirit, soul, ethereal body or just entity. We prefer to call it soul, because we refer especially to what can be felt and what are the consequences of our actions. This glowing orb represents in fact our essence and is made of a finer material, so it can move very easily inside the body.

There are authors who suppose that the glowing orb is in fact our soul (Petre, 2014; Klaus and Miceal, 2007; Blackburn Losey, spiritlite.com; Identity Network Jeremy Lopez, 2011).

The important thing is that using this orb inside the body, we can perform various actions in order to repair ourselves and to have full control.

Because the glowing orb has a small mass, its natural location inside the body is in the region of the second energy center, in the abdomen. This location corresponds to the minimum potential energy inside the body. In older Asian texts, about 3000 years ago, it is stated that the second energy center, the orange gate, represents the location of the soul inside the body, because it is the first center of the emotions.

We would rephrase this statement. We can say that, because the natural location of the soul inside the human body corresponds to the second energy center, this center is the main center of the emotions. This statement has a crucial importance for our health and not only.

This glowing orb can be felt there by everybody. In bad situations, the sensations such as: "I felt an emptiness in my stomach", "It seems to me that I felt a node in my stomach", "It is as if somebody punched me in the stomach", "I felt a clew in my stomach", "My stomach turns upside down", or even "I have butterflies in my stomach", for the lovers, justify the previous statement. 
Or, feeling the things a little differently, the criminologist lieutenant Joe Kenda from the crime documentary television series "Homicide Hunter" (which airs on the Investigation Discovery network), analyzing a horrible multiple crime, told the others "My stomach dropped". Well, of course the stomach cannot drop, because it has nowhere to drop. The statement signifies instead that the soul is trying to escape the cruel reality by shifting upwards.

\section{The Electro Photonic Imaging Device Experiments and the Results}

A higher control of the human being is possible by controlling this glowing orb inside the human body. That means it is preferable to keep the glowing orb in the position of the second energy center for as long as possible (Mândrea, 2011; Mândrea, 2014).

The effect of such a control is a very good state of health and also a good physical and psychic state, as it results from the following measured data.

The results presented in Figure 3 are extracted from a recording of the article's first author, performed in July 2016 using the Electro Photonic Imaging Device.

Inside this device, the particles emitted by the fingers of a human being are registered with an optical camera system and then the data are sent to a computer to be analyzed.

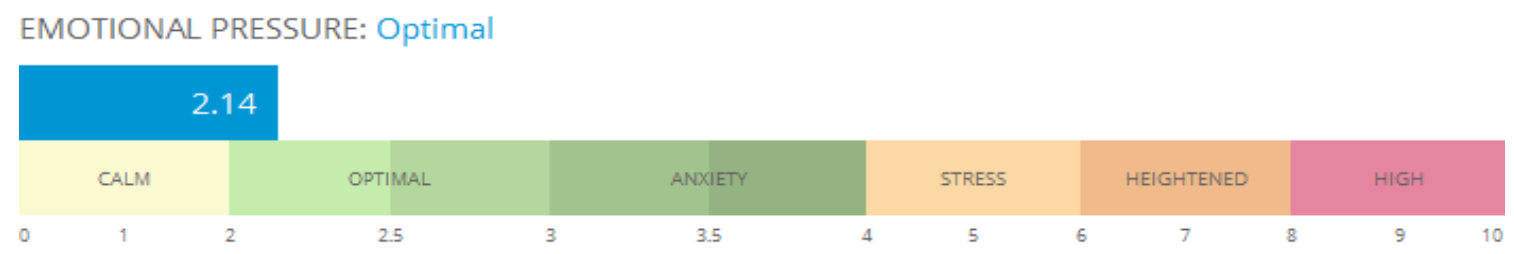

ENERGY: Optimal

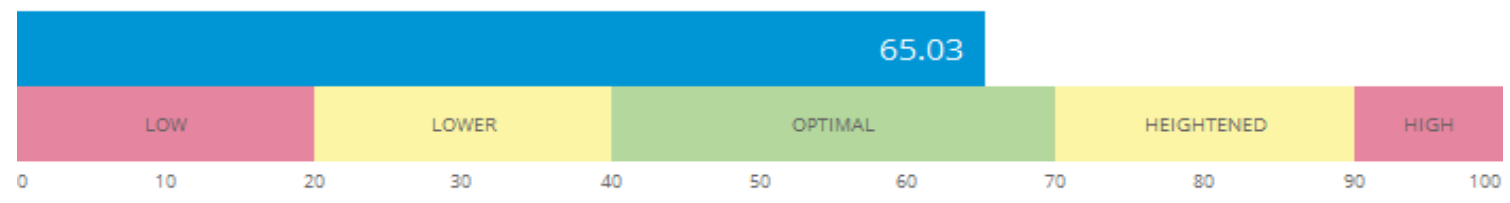

L/R SYMMETRY: Optimal

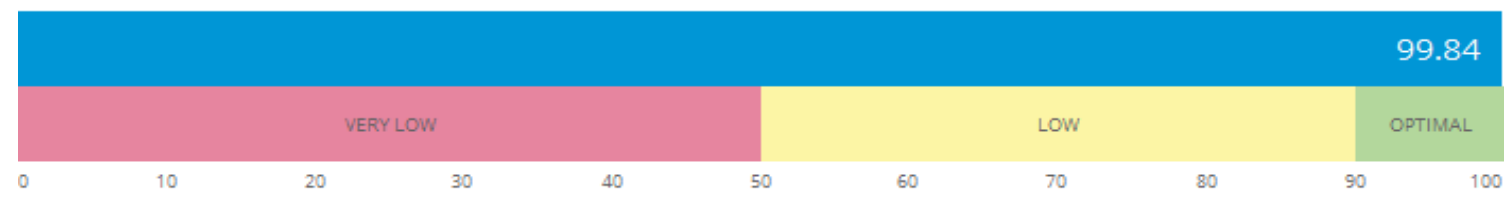

ORGANS BALANCE: Optimal

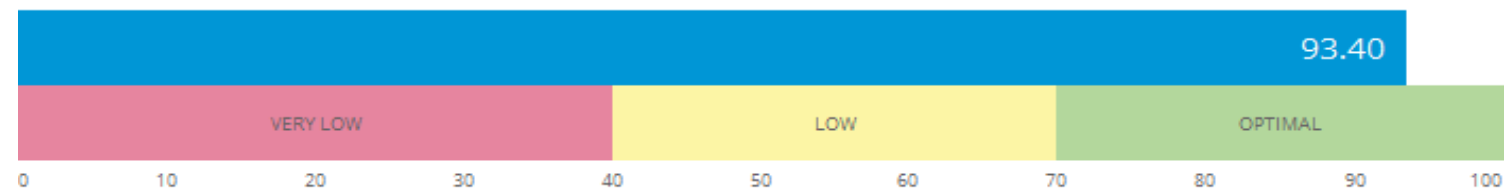

Figure 3. The Electro Photonic Imaging Device state data, recorded in July 2016 (Subject: Lucian MÂNDREA)

Source: Authors' own property.

The emotional state parameter is optimal to the calm level, with the value of 2.14 out of 10 . The energy parameter is optimal to the heightened level, with the value of 65.03 out of 100 .

The general balance state (Left/Right symmetry) parameter is optimal to the perfect level, with a value of $99.84 \%$, there missing only $0.16 \%$ for a perfect balance state to be achieved. The organs balance parameter is also optimal, with a value of 93.4\%. 
The same general state of the normal levels is also confirmed in Figure 4. The figure shows in the left part the general balance of the human being.

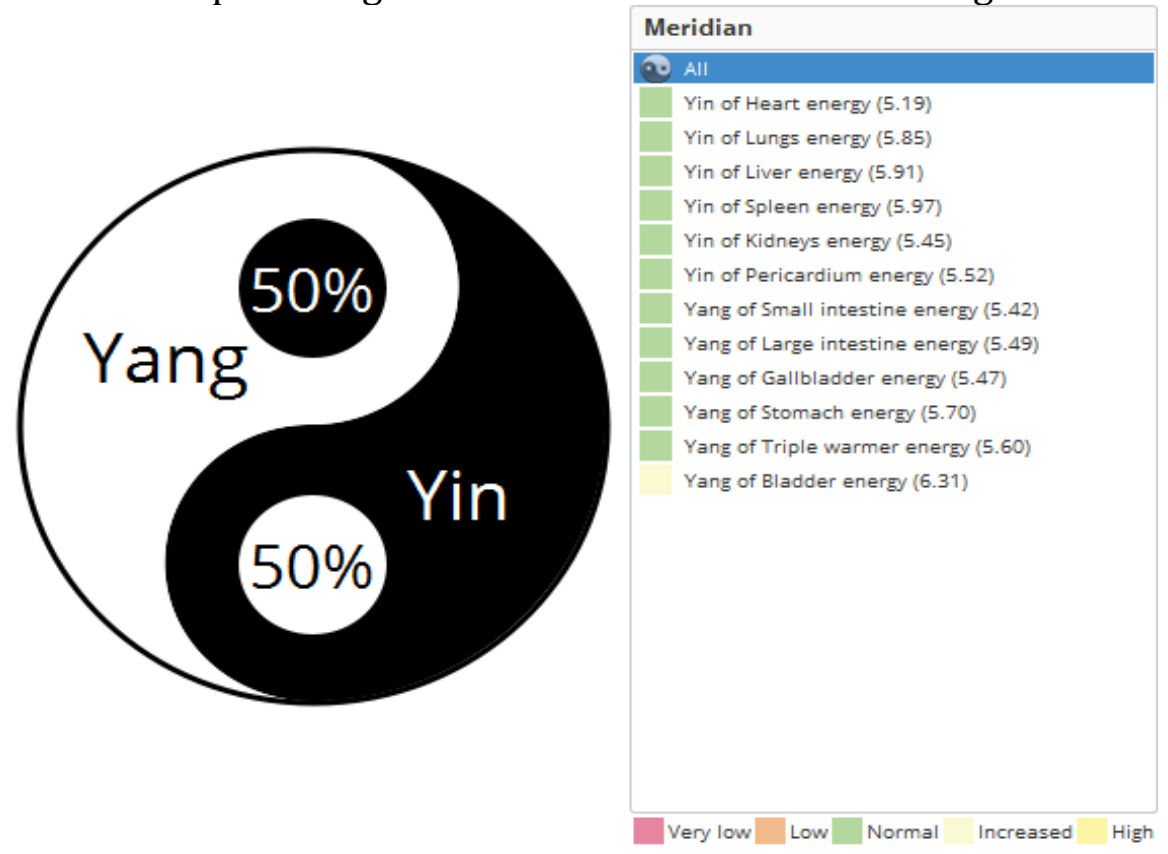

PICBE | 431

Figure 4. The Electro Photonic Imaging Device meridians data, recorded in July 2016 (Subject: Lucian MÂNDREA)

Source: Authors' own property.

In Figure 5 there are provided the results obtained at the personal state evaluation with the same Electro Photonic Imaging Device of the article's first author, but one year before, in July 2015.

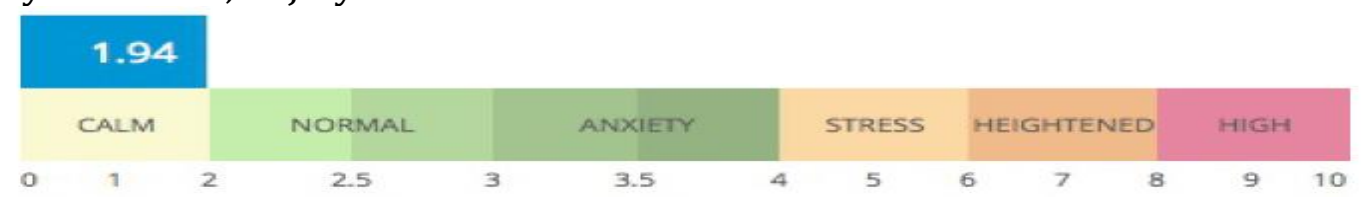

ENERGY: Normal

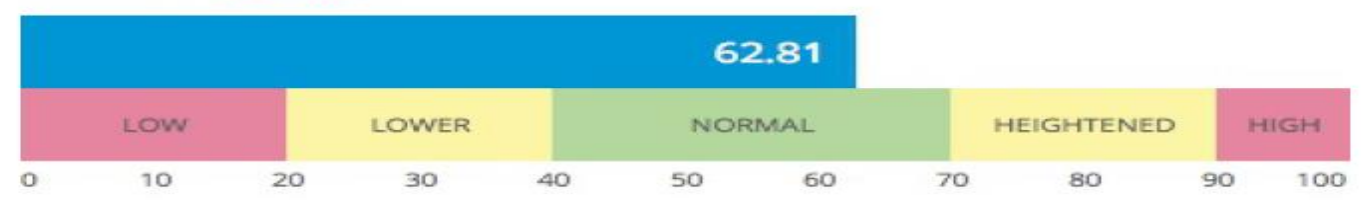

BALANCE: Normal

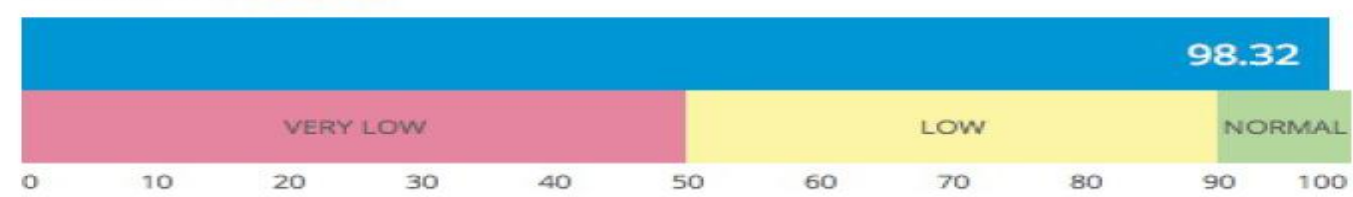

Figure 5. The Electro Photonic Imaging Device state data, recorded in July 2015 (Subject: Lucian MÂNDREA)

Source: Authors' own property.

By comparing the results from 2015 and 2016, one can notice that even if the subject has advanced in age with one year, the energy parameter value has increased with more than $2 \%$ (from $62.81 \%$ to $65.03 \%$ ), while the balance parameter value has also increased with more than $1.5 \%$ (from $98.32 \%$ to $99.84 \%$ ).

Returning to the results obtained in July 2016, in Figure 6 it is depicted the energy shell of the article's first author.

One immediately observes that the shell has no breaks, being very consistent. 

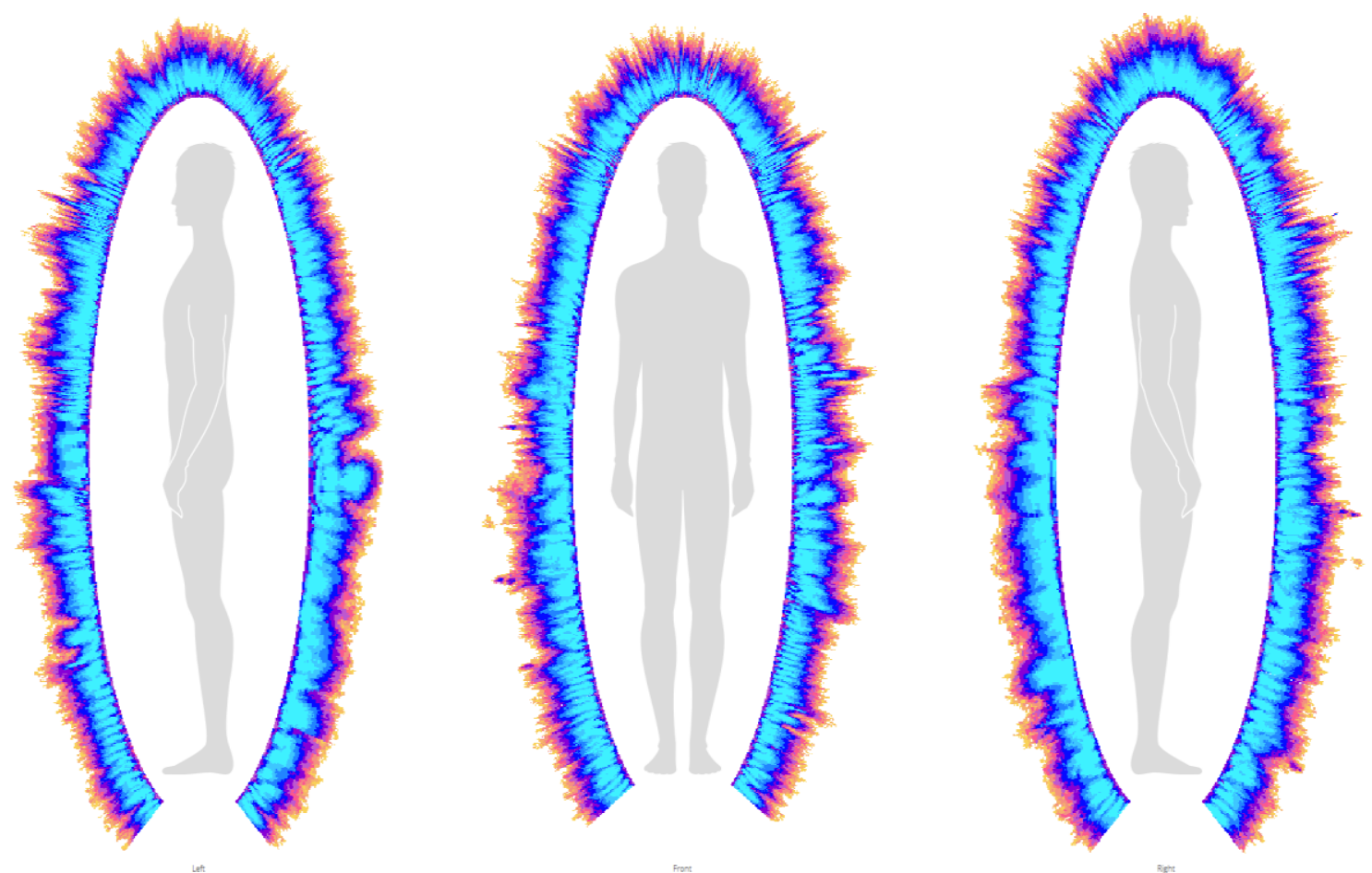

PICBE | 432

Figure 6. The Electro Photonic Imaging Device energy shell, recorded in July 2016 (Subject: Lucian MÂNDREA)

Source: Authors' own property.

With the EPI Device, data referring to the general health and the state of different organs were obtained.

In Figure 7 there are provided the data obtained for the internal organs during the same session (July 2016, the article's first author).

The red line represents the health state parameter, while the orange one represents the energy reserve level, which means how much energy the body is expected to have in the next future.

As long as the health parameter values stay on the green zone they are optimal. One can notice that the red line is around the middle of the green zone.

The energy values range between the green zone and light beige one, that is, there is a normal to high level of energy meaning that the subject is in a very good health and has very good expectance for the next future.

The two lines are far away from the burgundy color shade center zone, which corresponds to the illness states and even far from the next orange zone, which reflects the beginning of some health problems.

This analysis is called "The analysis of the back of the eye" in the classical medicine and is considered a complete analysis of the human being. 

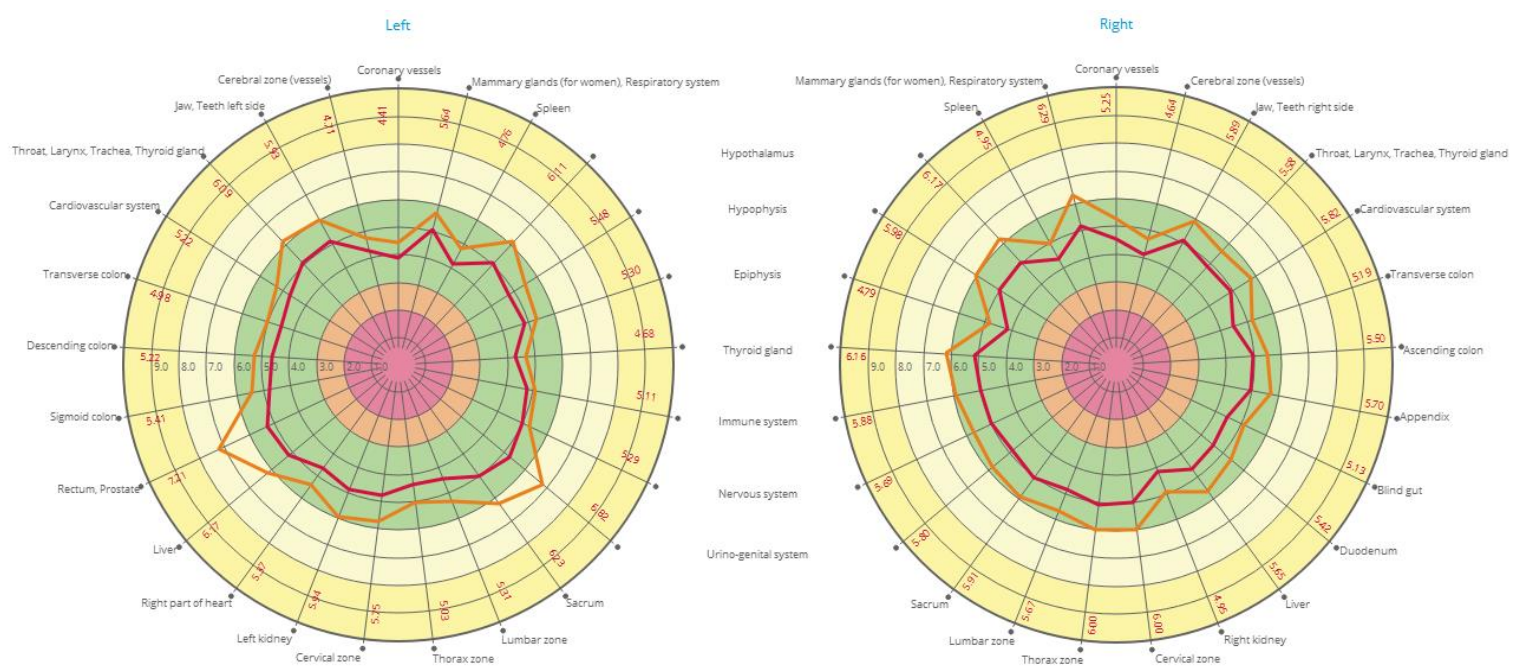

:BE $\mid 433$

Figure 7. The Electro Photonic Imaging Device internal organs data, recorded in July 2016 (Subject: Lucian MÂNDREA)

Source: Authors' own property.

In Figure 8 there are depicted the energy shells of each hand fingers (The article's first author). One can conclude that, again as in in Figure 6, the shells are very consistent and without breaks.

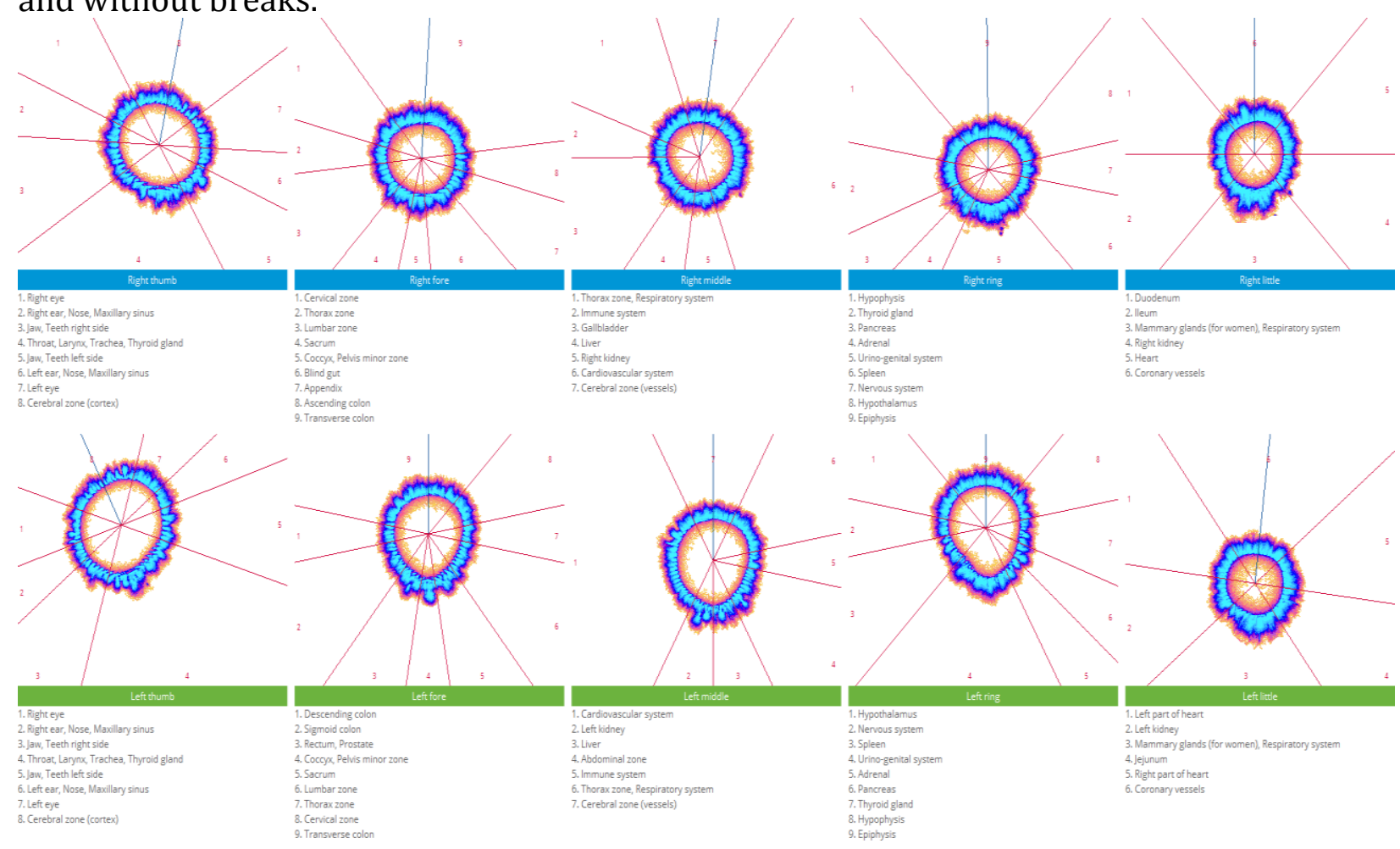

Figure 8. The Electro Photonic Imaging Device hand fingers energy shells, recorded in July 2016 (Subject: Lucian MÂNDREA).

Source: Authors' own property.

All the results that were gathered in July 2016 clearly reflect an additional activity of the analyzed subject (i.e. the article's first author) when compared to a human's ordinary activities, in order to maintain a continuous health and a special balance of the human being. 


\section{The Thermo Vision Experiments and the Results}

In what follows there are presented the results that have been gathered using the Thermo Vision Camera.

This time an experiment regarding the energy emission has been performed by the first author of the article in the role of the energy transmitter (See also Mândrea, Costea, Torp, 2015).

The energy has been emitted from the body with the help of the translucent orb towards the environment. The location of the energy emission has been around the second energy center of the human body, as previously discussed.

In Figure 9 there is presented the maximum temperature evolution during the whole experiment.

The maximum temperature value at the beginning has been of about $31.4^{\circ} \mathrm{C}$.

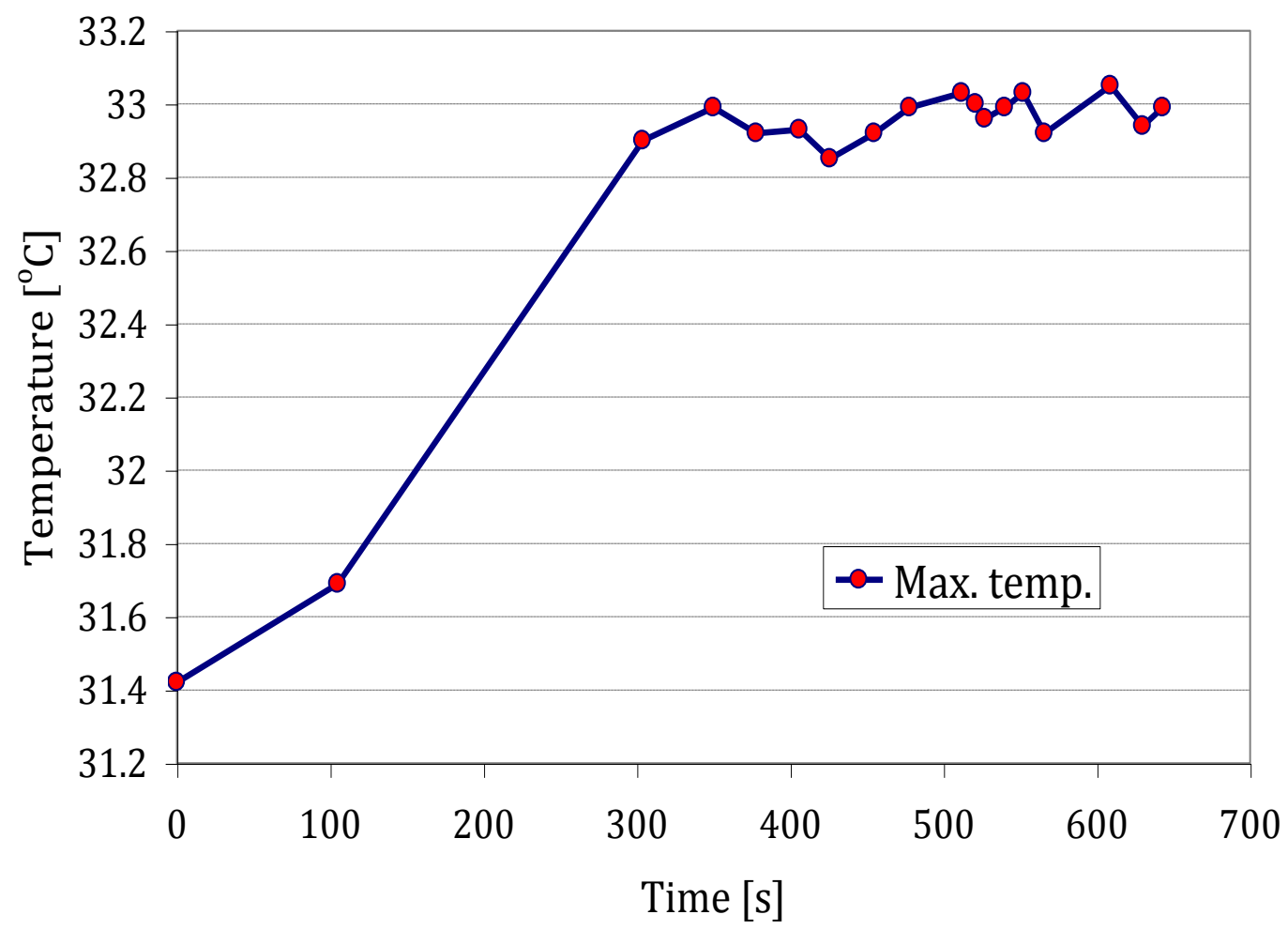

Figure 9. The temperature variation due to the energy emissions from the second energy center of the article's first author (Subject: Lucian MÂNDREA).

Source: Authors' own property.

The subject has emitted energy in sequences. This is the reason that ripples of the maximum temperature values appear.

The maximum recorded temperature during the experiment has been of $33^{\circ} \mathrm{C}$.

It is obvious that if emissions of energy are not produced, the temperature of the body will decrease in a room with a lower temperature. This is not the case in our experiment.

In Figure 10 there is shown the analyzed area after the beginning of the experiment (after 304 seconds, the third point on the plot shown in Figure 9).

The maximum temperature $\left(32.9^{\circ} \mathrm{C}\right)$ is measured around the umbilicus.

The thermal sensitivity (NETD / Noise Equivalent Temperature Difference) of the employed thermal vision camera is of $\leq 0.05^{\circ} \mathrm{C}$ at $30^{\circ} \mathrm{C}$ target temperature $(50 \mathrm{mK})$. 


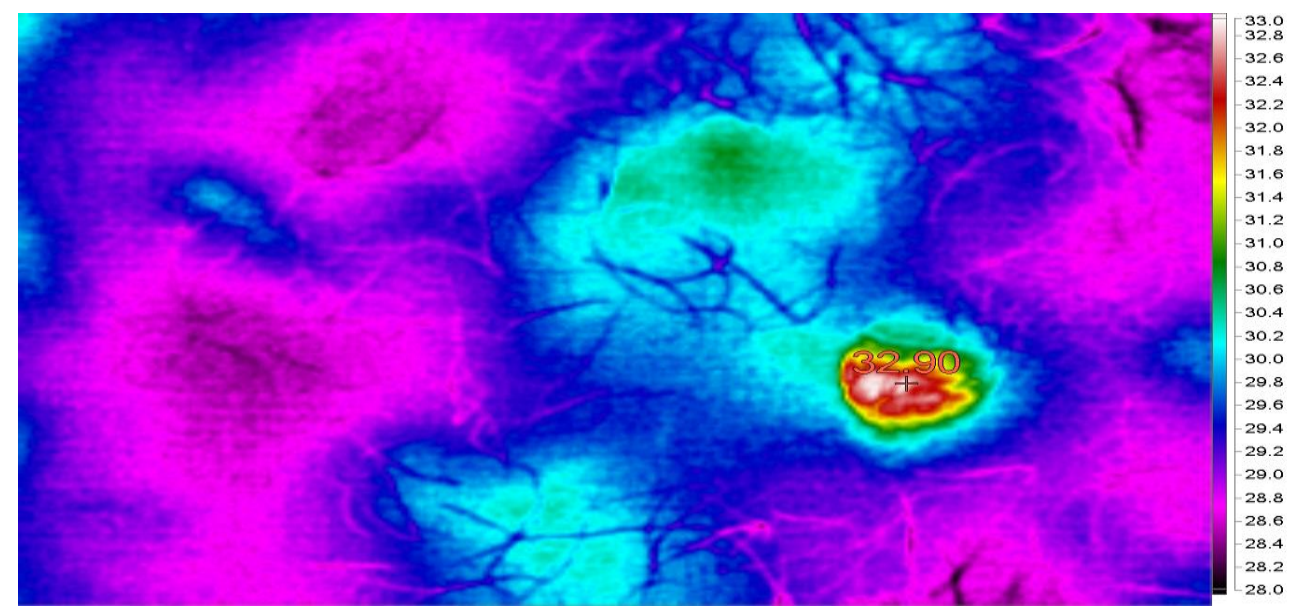

PICBE | 435

Figure 10. Thermal Vision Image of the second energy center of the article's first author after 304 seconds (The picture's left side is the upward direction, towards the head).

Source: Authors' own property.

In Figure 10 there is shown the analyzed area after 426 seconds that is the seventh point on the plot shown in Figure 11 (The maximum temperature value of $\left.32.85^{\circ} \mathrm{C}\right)$.

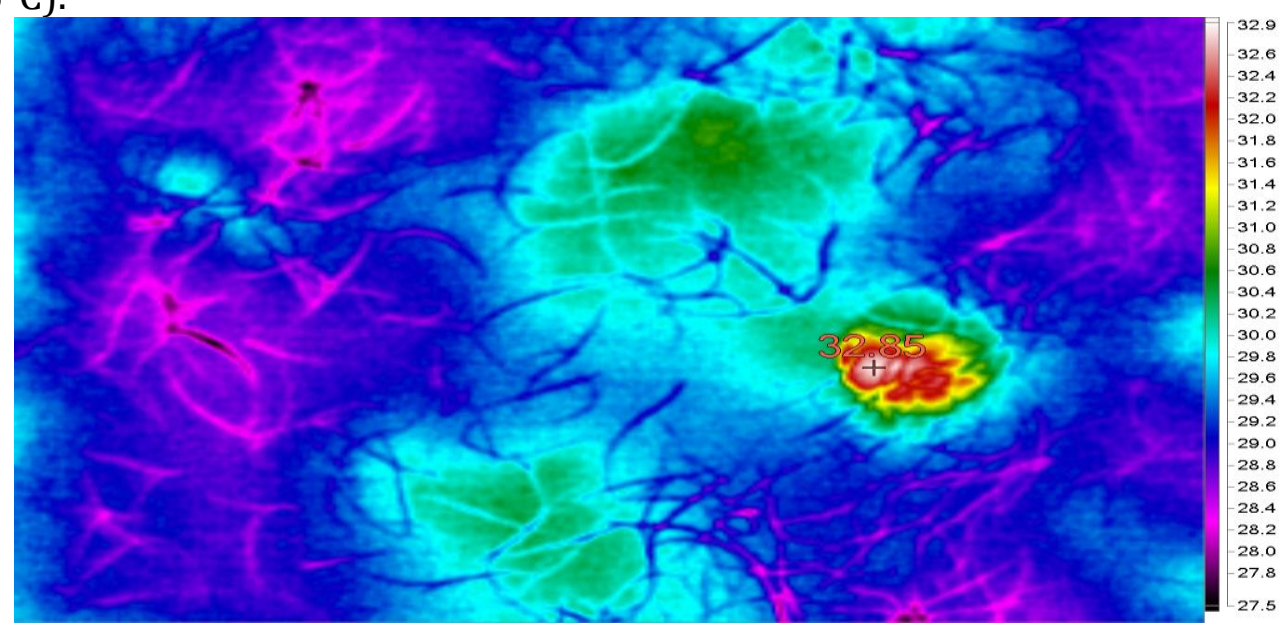

Figure 11. Thermal Vision Image of the second energy center of the article's first author after 426 seconds (The picture's left side is the upward direction, towards the head).

Source: Authors' own property.

Taking into account the previous presented aspects, the authors' advice is to have a thought on the following statement:

"Let us take the complete control of our human being as a whole!"

\section{Conclusions}

The classical medicine has its limitations because it only considers the physical body. The human being has only dense matter for atheists, who perceive the things only with the usual senses. For those who succeed in perceiving everything differently, there is a continuous interaction between the worlds and that supplementary something (i.e. glowing orb, soul, spirit, ethereal body, entity, etc.) can play an important role in our health, physical and psychic state and also in our happiness. The emotions, feelings and thoughts have a direct influence on the body's health as the glowing orb will respond by energy means. For example, in case of unfavorable emotions, the translucent orb leaves easily the abdomen and it shifts upwards, inside the physical body. It may even reach the above top of the head, through where it may leave away from the body, in particular circumstances. Such person reports for example a feeling of emptiness inside the 
stomach. In effect, this feeling needs to be compensated somehow and so the person begins to eat. Such people are suffering from bulimia. But conventional medicine does not know how to explain it, that it all starts from the lack of the translucent orb inside the abdomen. It is believed, however, that the negative emotions are the cause. Another typical example is the development of gastritis, ulcers, and possibly a perforated ulcer. Due to ongoing concerns related to facts or situations that create unfavorable emotions, the translucent orb directs the energy as a directional beam that destroys the energy shell, injures tissues and prepares the subject to disease. Afterwards, the bacteria will do their job. In case of small emotions the gastritis appears, while in case of large emotions the ulcer appears. Obviously, if emotions are even higher, and the subject does not find a way to get out of the unwanted situation then the perforated ulcer develops. In case of even higher annoyances related to life in general, the upwards shifting of the translucent orb inside the body is higher, for example, up to the fourth energy center, near the lungs. The energy directed by the translucent orb can weaken the lungs and you can end up with lung cancer. There are methods that can return the translucent orb back to its natural location (the second energy centre, close to the umbilicus). A common method is the abdominal breathing, which obviously improves the person's breath, but without the subject knowing, it facilitates the downwards shifting of the translucent orb.

All the presented important things can help everybody to obtain academic performances and a very good career in the future (Torp, Mândrea, Cipu, 2015).

For those who do not believe that we can do more, the practical results presented by the authors are justified by measurements and this should encourage them to challenge themselves more. For those who succeed in feeling the things differently and also in taking measures, leaving this world will represent a smaller problem.

\section{References}

Petre R.A. (2014) Globii luminoși din fotografii, Explicații fizice și paranormale, Ediția a doua, SPIRITUS.RO, Colecția MANIFESTĂRI ALE SPIRITELOR.

Klaus H., Miceal L. (November 6, 2007) The Orb Project, Paperback - Deckle Edge.

Meg Blackburn Losey, Magnificent Orbs, spiritlite.com.

Identity Network - Jeremy Lopez (2011), Soaking in the Light of the Spirit, (C) Copyright Identity Network, Inc. (885767857308).

Mândrea, L. (2011) Comportamentul sufletului în corpul uman, Editura Tornada.

Mândrea, L. (2014) Percepții extrasenzoriale. Sufletul în corpul uman, Editura Tornada.

Mândrea, L., Costea, M., Torp, A. (2015). The Energy Emissions Produced by the Human Being and their Practical Use. The $9^{\text {th }}$ International Symposium on ADVANCED TOPICS IN ELECTRICAL ENGINEERING, May 7-9, 2015, Bucharest, Romania, 260264.

Torp, A., Mândrea, L., Cipu, C. (2015). Electro Photonic Imaging - A Possible Predicting Factor for Academic Performance. Energy Education Science and Technology Part A: Energy Science and Research, 33(6), 3159-3166. 